\title{
Cellular Pharmacology of Curcumin With and Without Piperine
}

Rama I Mahran ${ }^{1,2}$, Pan Shu³, Justin Colacino ${ }^{4}$, Magda M Hagras², Duxin Sun ${ }^{3}$,

Dean E Brenner ${ }^{1 *}$

${ }^{I}$ Division of Hematology-Oncology, Department of Internal Medicine, Medical School, University of Michigan, Ann Arbor, MI

${ }^{2}$ Department of Pharmacology, College of Medicine, Suez Canal University, Ismailia, Egypt

${ }^{3}$ Department of Pharmaceutics, College of Pharmacy, University of Michigan, Ann Arbor, MI

${ }^{4}$ Department of Environmental Health Sciences, University of Michigan School of Public Health, 6630 SPH Tower, 1415 Washington Heights, Ann Arbor, MI 48109, USA

Correspondance:

Dean E Brenner

2150 Cancer Center

University of Michigan Medical Center

Ann Arbor, MI 48109-5290

Email: $\underline{\text { dbrenner@umich.edu }}$

Telephone: (734) 647-1417

Fax: (734) 647-9817 


\title{
Cellular Pharmacology of Curcumin With and Without Piperine
}

\author{
Abstract \\ Prior reports have suggested that piperine enhances curcumin's anti-carcinogenesis. We tested \\ the hypothesis that piperine increases the intracellular concentrations of curcumin by improving \\ intracellular uptake or reducing curcumin efflux or metabolism in breast cells. We incubated \\ SUM149, MCF10A, primary normal human breast cells, $\mathrm{ALDH}^{+}$, and $\mathrm{ALDH}^{-} \mathrm{CD} 44^{+} 24^{-}$ \\ SUM149 cells with curcumin \pm piperine at concentrations $1 \mu \mathrm{M}$ to $15 \mu \mathrm{M}$ for time periods of 15 \\ minutes to 24 hours. We assayed cell viability by MTT assay and proliferation by primary \\ mammosphere assay. Curcumin and its metabolites were assayed using liquid chromatography \\ mass spectroscopy. Curcumin, but not piperine, showed significantly higher effects on the \\ viability of breast cancer SUM149 cells than in non-tumorigenic MCF10A cells. Curcumin + \\ piperine synergistically reduced viability of SUM149 cells but had a concentration dependent \\ effect upon MCF10A cell viability. Cellular uptake of curcumin in SUM149 is significantly \\ higher, while the efflux in SUM149 is significantly lower than in MCF10A, which correlated \\ with cell viability. Piperine did not alter curcumin cellular uptake, efflux, or metabolism in any \\ of the cell models. The observed synergism of piperine+curcumin in reducing breast stem cell \\ self renewal is likely due to independent anti-carcinogenesis effects rather than any effects upon \\ intracellular curcumin concentrations.
}

Key Words: Curcumin, piperine, chemoprevention 


\section{Introduction}

Curcumin - the major bioactive product extract from the rhizome of the Curcuma longa plant (turmeric) — has a wide spectrum of anti-carcinogenic, antioxidant (1), anti-inflammatory (1), and cancer chemopreventive effects in colon cancer (2), breast cancer (3), and other types of cancers (4). The molecular mechanisms by which curcumin exerts these broad biological effects are diverse and include inhibition of eicosanoid synthesis $(5,6)$, inhibition of NFkB release $(5$, $6)$, inhibition of stemness through interruption of Wnt signaling $(5,7,8)$, modification of cellular lipid profiles (9), modification of P-glycoprotein expression (10), and inhibition of vascular endothelial growth factor (VEGF)-mediated angiogenesis $(5,6)$. This broad group of anticarcinogenesis mechanisms has translated into potent chemopreventive effects in classical chemical in vivo rodent carcinogenesis models of diverse organ systems $(3,11-14)$ as well as in transgenic rodent carcinogenesis systems $(3,14-16)$.

Despite a broad anti-carcinogenesis effect in preclinical modes, curcumin has not found a role in clinical cancer prevention, primarily due to poor bioavailability in humans. To address this barrier, investigators have sought to enhance absorption and systemic bioavailability by inhibiting cell membrane efflux transporters, reducing metabolism and conjugation by inhibiting Phase I and II metabolizing enzymes by using bioenhancers $(4,17)$, creating novel delivery systems to overcome first pass extraction and rapid systemic metabolism $(4,18)$, and by synthesizing analogs or conjugates to enhance curcumin's solubility and stability while retaining its pharmacological properties.

Piperine, an alkaloid extract from pepper, has been studied in vivo as a bioenhancer of curcumin because of its inhibitory properties on cellular membrane efflux transporters (19-21) and phase I and phase II metabolizing systems (20, 22-26). An early clinical trial of piperine 
combined with curcumin (17) suggested that piperine enhanced curcumin's systemic bioavailability. More recent data using contemporary analytical technologies and Good Manufacturing Practices compliant formulations have failed to reproduce these initial findings (27-29).

We found that piperine alone inhibits normal human breast mammosphere formation (7, 30). In combination with curcumin, piperine enhanced curcumin inhibition of primary normal human breast epithelial $\mathrm{ALDH}^{+}$cells via inhibition of the Wnt signaling pathway (7). These data suggested that piperine's interaction with curcumin may be independent of its bioenhancer activity. Data in cell culture systems support piperine's anti-carcinogenic activity. For example, piperine inhibits activator protein $1(\mathrm{AP}-1)$ and nuclear factor- $\kappa \mathrm{B}(\mathrm{NF}-\kappa \mathrm{B})$ through the inhibition of ERK1/2, p38 MAPK, and Akt signaling pathways in SKBR breast cancer cells (31). Piperine inhibits Wnt $\beta$-catenin signaling pathway in colorectal cancer cells (32).

The issue of whether piperine functions as a bioenhancer of curcumin's anti-carcinogenic activity or as an independent anti-carcinogen with additive or synergistic activity with curcumin remains unresolved. Here we addressed the question of whether piperine's enhancement of curcumin's anti-carcinogenic activity is due to enhancement of piperine's cellular uptake of curcumin or is due to independent, additive or synergistic anti-carcinogenesis effect. 


\section{Materials and Methods}

\section{Chemicals}

Curcumin (>90\% pure) was purchased from Cayman (Ann Arbor, MI) and piperine (>99\% pure) was purchased from Sigma Aldrich (St. Louis, MO). Stock solutions of curcumin and piperine were prepared in dimethyl sulfoxide (DMSO), prepared to a concentration of $50 \mathrm{mM}$ and stored in $-80{ }^{\circ} \mathrm{C}$. Curcumin O-sulfate $(\mathrm{COS}>95 \%$, w/w) was purchased from Toronto Research Chemicals (Toronto, Ontario) and tetrahydrocurcumin was purchased from Santa Cruz Biotechnology (Dallas, TX). The internal standard CE302 (>98\%, w/w) was synthesized in the University of Michigan Pharmacokinetic Core lab and was used without further purification. HPLC grade acetonitrile and formic acid were obtained from Sigma Aldrich; Methanol was purchased from Thermo Fisher Scientific (Waltham, MA). HPLC grade water was obtained via a Milli-Q Integral Water Purification System (Darmstadt, Germany).

\section{Cell Lines}

The MCF10A human breast cell line was purchased from ATCC (Manassas, VA). SUM149 was purchased from Asterand (Detroit, MI). MCF10A was cultured in DMEM/F12 lonza (Walkersville, MD) supplemented with 5\% horse serum, insulin $(10 \mu \mathrm{g} / \mathrm{mL})$, epidermal growth factor $(20 \mathrm{ng} / \mathrm{mL})$, cholera toxin $(100 \mathrm{ng} / \mathrm{ml})$, and gentamycin $(50 \mathrm{ng} / \mathrm{mL})$. SUM149 cells were cultured in DMEM/F12 Lonza supplemented with 5\% fetal bovine serum, insulin (5 $\mu \mathrm{g} / \mathrm{mL})$, and hydrocortisone $(1 \mathrm{mg} / \mathrm{mL})$.

\section{Normal Human Breast Mammosphere Assay}

\section{Normal Human Breast Tissue Dissociation}

Normal human breast tissue was obtained from 15 women who were undergoing elective reduction mammoplasty. After providing informed consent (following the University of 
Michigan IRBMED approved tissue collection protocol), the tissue was obtained through the Tissue Procurement Service with the Department of Pathology at the University of Michigan Medical School. The breast tissue of 15 patients was mechanically and enzymatically dissociated into single cells as previously described (33).

\section{Mammosphere Formation}

Pooled breast epithelial single cells from 15 patients were cultured in MammoCult media (Stem Cell Technologies, Vancouver, Canada) and treated with curcumin, piperine, or both or the DMSO control $(0.1 \%)$ in triplicates/dose/combination. Cells were plated in 6-well ultralow attachment plates (Corning Inc, Corning NY) at a density of 100,000 cells/mL. Primary mammospheres were allowed to form for 10 days. The mammospheres' size was measured using Spot Imaging Software. The mammospheres that were $40 \mu \mathrm{m}$ or larger were counted manually by two independent observers. The average number and size of mammospheres for each treatment were calculated. The experiment was repeated three times.

\section{Cell Viability Assay}

MCF10A and SUM149 cells were plated at a density of $3 \times 10^{3}$ cells/well in 96 well plates. The next day, the cells were treated with increasing concentrations of curcumin $(0-20 \mu \mathrm{M})$ or piperine $(0-200 \mu \mathrm{M})$ or both or the DMSO control $(0.1 \%)$ in 6 replicates for each dose or combination, and the cells were incubated for 72 hours. A MTT assay (American Type Culture Collection (ATCC)) was performed per the manufacturer's instructions. The absorbance of the colored solution was measured using the plate reader (Synergy multimodal reader) at $570 \mathrm{~nm}$ wavelength. 


\section{Stability of Curcumin \pm Piperine in Complete media and PBS}

To determine the type of solvent that would be used in the uptake experiments, we pipetted curcumin into complete media (containing 5\% FBS), MammoCult media, or PBS to reach a concentration of $15 \mu \mathrm{M}$ (the highest curcumin concentration used in the uptake experiments), and the solutions were vortexed well. The solutions were incubated and protected from light at $37{ }^{\circ} \mathrm{C}$ (to mimic the cellular incubation conditions) for $0,0.08,0.16,1,4$, and 8 hours. At each time point, the solutions were vortexed; curcumin and its degradation products were extracted and analyzed by the LC-MS system.

To determine the effect of piperine on curcumin stability, solutions of $15 \mu \mathrm{M}$ curcumin \pm $10 \mu \mathrm{M}$ piperine were prepared in $\mathrm{PBS}$ and incubated at $37^{\circ} \mathrm{C}$ protected from light for $0,5,10$, and 60 minutes. At each time point, the solutions were vortexed; curcumin was extracted from each solution and quantified by LC-MS. The experiment was repeated three times.

\section{Cellular Uptake, Efflux and Metabolism of Curcumin \pm Piperine}

Our data (Figure 1) and those of others $(34,35)$ show that curcumin is unstable in the physiological buffer. Although MammoCult media is considered serum free media, the stability of curcumin in this type of media was comparable to complete media. In vitro experiments were performed in complete media (containing 5\% serum).

\section{Cellular Uptake}

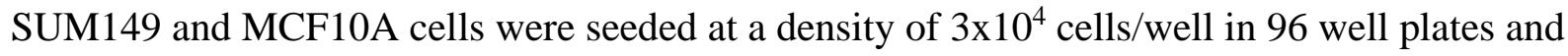
left to attach overnight. The following day, the cells were washed and incubated with warm HBSS for 2 minutes. The HBSS was then replaced by $15 \mu \mathrm{M}$ curcumin $\pm 10 \mu \mathrm{M}$ piperine for 30 , $60,120,240$, and $360 \mathrm{~min}, 1 \mu \mathrm{M}$ curcumin $\pm 1 \mu \mathrm{M}$ piperine, or $5 \mu \mathrm{M}$ curcumin $\pm 5 \mu \mathrm{M}$ piperine for 5, 10 and 60 minutes or the DMSO control in complete media alone for 24 hours. Each dose 
or combination was performed in triplicates (triplicates/dose/combination). At each time point, the media was removed, extracted by methanol and kept at $-80^{\circ} \mathrm{C}$ for assay of curcumin, metabolites, and degradation products using liquid chromatography-mass spectroscopy (LCMS). The cell monolayer was washed with cold HBSS three times and lysed by adding 50 $\mu \mathrm{L} /$ well of $1 \mathrm{X}$ radioimmuno-precipitation assay (RIPA) cell lysis buffer (Santa Cruz Biotechnology). The plates were maintained at constant agitation at $4^{\circ} \mathrm{C}$ for 20 minutes, and the cell lysates were collected and sonicated while on ice for 15 seconds using medium power. The extract was assayed by the LC-MS. Protein concentrations in the cell lysates $(\mathrm{mg} / \mathrm{mL})$ were assayed using the Bradford protein assay (Bio-Rad, Hercules, CA) per the manufacturer's instructions. Curcumin concentrations were normalized to protein concentration. To assess whether pre-treatment with piperine might alter the cellular uptake of curcumin, MCF10A cells were plated at a density of $3 \times 10^{4}$ cells/well in 96 well plates and incubated overnight to attach. The following day, the cells were washed with HBSS, incubated with increasing concentrations of piperine $(0-50 \mu \mathrm{M})$ in warm HBSS, and incubated for 30 minutes. After 30 minutes, HBSS was replaced by $15 \mu \mathrm{M}$ curcumin dissolved in complete media, and the cells were incubated for 2 hours. After 2 hours, the media was removed, the cell monolayer washed, lysed, and extracted to be analyzed by LC-MS.

To understand cellular uptake of curcumin in the presence and absence of piperine in a model system where we observed significant effects in primary breast cells, we used pooled primary normal human breast cells obtained from 15 patients undergoing mammoplasty procedures. Pooled cells were seeded at the density of $2 \times 10^{5}$ cells/well in 24 -well ultralow attachment plates in MammoCult media, treated with $15 \mu \mathrm{M}$ curcumin $\pm 10 \mu \mathrm{M}$ piperine or DMSO control in triplicate/dose/combination and incubated for $0.5,1,2,4$, and 6 hours. At each 
time point, the cells were collected and washed twice with cold HBSS. The cell pellet was lysed by $100 \mu \mathrm{L}$ RIPA lysis buffer, and then proceeded with the LC-MS analysis.

\section{Cellular Efflux}

We incubated SUM149 cells and MCF10A cells (in 2D culture) with $15 \mu \mathrm{M}$ curcumin $\pm 10 \mu \mathrm{M}$ piperine for 1 hour, then the media containing the drugs was removed, the cell monolayer was washed twice, then incubated with fresh media with or without $10 \mu \mathrm{M}$ piperine for $0.08,0.25$, $0.5,1,2$, and 4 hours. At each time point, the media was removed and extracted, the cells were lysed and extracted and proceeded with the LC-MS analysis as described above.

\section{Assessing Curcumin Uptake in Breast Stem Cells}

There are two major populations of breast stem cells: Cells that carry the surface marker of $\mathrm{CD} 44^{+} \mathrm{CD} 24^{-}$and others which express aldehyde dehydrogenase $\left(\mathrm{ALDH}^{+}\right)(36)$. We purified $\mathrm{ALDH}^{+}$and $\mathrm{CD} 44^{+} \mathrm{CD} 24^{-}$cells as well as the non-stem cells from SUM149 cells using MoFlo Astrios flow cytometer (FACS) as described previously (30). Single SUM149 cells were stained by Alexafluor750 LIVE/DEAD Fixable Dead Cell Stain (Life Technologies, Carlsbad, CA), CD24-Brilliant Violet 421 (Biolegend, San Diego, CA), CD44-APC (Biolegend), and Aldefluor (Stem cell Technologies). For compensation and gating purposes, single stain and isotype controls were included. $\mathrm{ALDH}^{+}, \mathrm{CD}_{4} 4^{+} \mathrm{CD} 24^{-}, \mathrm{ALDH}^{-}, \mathrm{CD} 44^{+} /{ }^{-} \mathrm{CD} 24^{+}$were sorted by FACS. $\mathrm{ALDH}^{+}$and $\mathrm{ALDH}^{-} \mathrm{CD} 44^{+} \mathrm{CD} 24^{-}$cell populations, and the remaining SUM149 cells that didn't express any of these markers (non-stem cells) were seeded at a density of 3x10 $10^{4}$ cells/well in 96 well plates and incubated overnight. The next day, the cells were treated with $15 \mu \mathrm{M}$ curcumin \pm $10 \mu \mathrm{M}$ piperine for one hour, then washed, lysed, and extracted for LC-MS analysis. 


\section{Liquid Chromatography-Mass Spectroscopy (LC-MS) Assay for Curcuminoids, Metabolites}

\section{and Degradation Products}

We used a LC-MS method to separate and directly quantify curcuminoids (curcumin, demethoxycurcumin, and bisdemethoxycurcumin), curcumin metabolites (curcumin sulfate conjugates, and tetrahydrocurcumin), curcumin degradation products (bicyclopentadione and ferulic acid), and internal standard 7-(3,5-dimethylisoxazol-4-yl)-6-methoxy-2-methyl-N-(1methyl-1H-pyrazolo[3,4-b]pyridin-3-yl)-9H-pyrimido[4,5-b]indol-4-amine (CE302).

Sample Preparation, Extraction and Analyte Stability

Stock solutions of curcumin was prepared in DMSO at a concentration of $50 \mathrm{mM}$ and stored at $-80{ }^{\circ} \mathrm{C}$. To prepare a calibration curve, an aliquot of $15 \mu \mathrm{L}$ of diluted standard solution in methanol (a mixture of curcumin, tetrahydrocurcumin, and curcumin sulfate each 1-5000 $\mathrm{ng} / \mathrm{mL}$ ) was spiked into an aliquot of $15 \mu \mathrm{L}$ blank cell lysate and media to yield cell lysate and media samples containing $1-5000 \mathrm{ng} / \mathrm{mL}$ standards, respectively. The lysates or media (15 $\mu \mathrm{L})$ was mixed with $15 \mu \mathrm{L}$ of methanol. These samples were extracted with $100 \mu \mathrm{L}$ of internal standard solution dissolved in methanol, by vortexing and centrifuging at $2000 \mathrm{x} \mathrm{g}$ for $10 \mathrm{~min}$. at $4{ }^{\circ} \mathrm{C}$. An aliquot of $5 \mu \mathrm{L}$ supernatant was used for the LC-MS/MS analysis.

There is no available bicyclopentadione standard, therefore, we quantified the bicyclopentadione against the standard curve of curcumin sulfate, as described (37). We performed curcumin stability experiments by comparing peak size, area, and fragmentation of curcumin assayed from $15 \mu \mathrm{M}$ stock solution in either complete media containing $5 \%$ fetal bovine serum or standard phosphate buffered saline kept at $37^{\circ} \mathrm{C}$ for $0,5,10,60,240$, and 480 minutes protected from light. Solutions of $15 \mu \mathrm{M}$ curcumin $\pm 10 \mu \mathrm{M}$ piperine were prepared in PBS and incubated at $37^{\circ} \mathrm{C}$ protected from light for $0,5,10$, and 60 minutes. 


\section{Equipment}

LC-MS was performed on a Shimadzu HPLC system (Shimadzu) consisting of a SCL-20A system controller, two LC-20AD pumps, and an SIL-20AD auto-sampler. Chromatographic peaks were monitored through an API 5500 Qtrap mass spectrometer equipped with an electrospray ionization quadrupole mass analyzer (AB Sciex LLC, Framingham, MA). Analyst software (Version 1.6.2) was used for system control and data processing.

\section{Analytical Methodology}

The analytes were separated in a mobile phase consisting of two components: mobile phase A, $0.1 \%$ formic acid in water and mobile phase $\mathrm{B}, 0.1 \%$ formic acid in acetonitrile. The gradient profile was $0-30 \mathrm{~min}, 85-0 \%$ mobile phase A linear; the flow rate was $0.7 \mathrm{~mL} / \mathrm{min}$. The optimized system parameters were obtained via direct infusion of standard solutions, respectively. The ion transition pairs for the quantification of curcumin were selected based on the highest multiple reaction monitoring $(\mathrm{MRM})$ signal under positive $(+)$ mode. The screening and identification of curcumin metabolites were carried out under negative (-) mode for better ionization.

\section{Data Analysis}

The percent of curcumin concentration in complete media and PBS at each time point relative to its concentration at time zero was calculated as follows: (The peak area ratio of curcumin to the IS peak area in the solution at specific time point/ the peak area ratio of curcumin to the IS peak area at time zero) $\mathrm{x}$ 100\%. To calculate the half-life of curcumin in complete media and in PBS, we added exponential trendlines to the generated graphs in Microsoft Excel and the equations generated from these trendlines were used to estimate that half-lives. 
To calculate the percent of cell viability in the MTT assays, the average absorbance of each treatment was divided by the average absorbance of the DMSO control and was then multiplied by $100 \%$.

To determine the nature of the interaction between curcumin and piperine, the combination index (CI) theorem based on the Median-Effect Equation (38) was used. Combination indices were calculated using the Compusyn software (ComboSyn Inc.), and $\mathrm{r} \geq$ 0.95 was considered a simulation for the dose-effect relationship. A CI between 0 and 0.9 indicates synergy; a CI between 0.9 and 1.1 indicates an additive effect, and a CI with a value from 1.1 to infinity indicates an antagonistic interaction (39-41). The IC50 of curcumin and piperine were also calculated by Compusyn software. To calculate the ratio of curcumin mass detected in the media to its mass intracellular, we calculated the mass of curcumin in the cell lysates and in the media by multiplying the concentration of curcumin $(\mathrm{ng} / \mathrm{mL})$ by the volume of the cell lysates $(0.05 \mathrm{~mL})$, or the volume of media $(0.1 \mathrm{~mL})$. Then, we divided the mass of curcumin in the media by mass of curcumin in the cells.

Data are expressed as mean \pm standard deviation. The following data were compared between groups using Student's T test: IC50 of curcumin and piperine in MCF10A versus SUM149 and mammosphere formation, and the intracellular curcumin concentrations at each time point. The intracellular curcumin concentration, curcumin and its metabolites in the media of the cell models studied were compared between groups using a one-way analysis of variance (ANOVA) using SPSS 17.0 with adjustment to multiple comparison with the Bonferroni method. A p value $<0.05$ was considered significant. 


\section{Results}

\section{Piperine Does Not Enhance Curcumin Stability}

One potential explanation for piperine enhancement of curcumin anti-carcinogenic effect might be that piperine stabilizes the curcumin molecule in physiologic conditions. Curcumin degrades rapidly in PBS reaching 50\% of its original concentration after $0.62 \pm 0.002$ hours (Figure 1A). In complete cell culture media, curcumin is stable for 1 hour with a slower degradation rate over time than in PBS. Curcumin's half-life in complete media is $6.53 \pm 0.46$ hours. The decrease of curcumin concentration over time in the PBS and in complete cell culture media was accompanied by an increase of curcumin's major degradation products, especially bicyclopentadione (Figure 1B) and ferulic acid (data not shown). We found bicyclopentadione and ferulic acid intracellularly and in the incubation cell culture media (Data not shown).

Addition of piperine to curcumin in PBS did not protect curcumin from degradation (Figure 1C). [Figure 1 should be near here]

\section{Effects Upon Cell Viability of Invasive and Non-Invasive Cell Lines}

We measured the effects of a 72 hour treatment of curcumin $(0-20 \mu \mathrm{M})$ and piperine $(0-200 \mu \mathrm{M})$ on cell viability in SUM149 and MCF10A cells, comparing the effects to the DMSO controls. The IC50 was $8.75 \pm 0.15 \mu \mathrm{M}$ (mean \pm standard deviation) (Figure $2 \mathrm{~A}$ ) and $94.8 \pm 5.3 \mu \mathrm{M}$ (Supplemental Figure 1) for curcumin and for piperine ( $\mathrm{p}$ value of IC50 of curcumin compared to piperine<0.001) respectively in SUM149 cells. In SUM149 cells, the combination index (CI) analysis provides evidence of synergism at most curcumin concentrations (Figure 2B). Higher curcumin concentrations $(\geq 20 \mu \mathrm{M})$ alone are cytotoxic, thus no synergism can be assessed at those concentrations. The IC50 was $15 \pm 0.4 \mu \mathrm{M}$ (Figure $2 \mathrm{C}$ ) and $114 \pm 14.3 \mu \mathrm{M}$ (Supplemental Figure 1) for curcumin and piperine, respectively in the MCF10A cells ( $p<0.001)$. While 
MCF10A cells are more resistant to the cytotoxic effects of curcumin compared to SUM149 (p value of the IC 50 of curcumin's cytotoxicity in MCF10A compared to SUM149=0.004). Combination index analysis suggests additive effects of piperine to curcumin's effects in MCF10A cells (Figure 2D). Curcumin-piperine cytotoxic interaction is less pronounced in the non-invasive MCF10A cells than in SUM149 cells (Figure 2B and D) with synergy demonstrated only between curcumin and piperine at the lower concentrations of both drugs. [Figure 2 should be near here]

\section{Effects Upon Primary Human Mammosphere Formation}

We repeated and verified our previously published data (7) that curcumin and piperine additively inhibits normal human breast stem cell self-renewal using a mammosphere assay as a surrogate for breast stem cell self-renewal (Supplemental Figure 2).

\section{Cellular Uptake}

Previous report suggested that piperine acts as a bioenhancer of curcumin by increasing its intracellular concentration (17). We found no significant increase in curcumin uptake with piperine incubation in MCF10A cells, SUM149 cells, or in the primary normal human breast cells after six hours of incubation with curcumin $15 \mu \mathrm{M} \pm$ piperine $10 \mu \mathrm{M}$ (Figure $3 \mathrm{~A}$ ) or curcumin $5 \mu \mathrm{M} \pm$ piperine $5 \mu \mathrm{M}$ (SUM149 and MCF10A only) (Figure 3B). Preincubating MCF10A breast cells with increasing concentrations of piperine (from $1 \mu \mathrm{M}-50 \mu \mathrm{M}$ ) for 30 minutes prior to the addition of $15 \mu \mathrm{M}$ curcumin for 2 hours did not increase curcumin's cellular uptake (Data not shown). [Figure 3 should be near here]

Intracellular concentrations of curcumin in SUM149 cells were significantly higher than MCF10A cells (Figure 3). For example, after 1 hour of incubation with $5 \mu \mathrm{M}$ curcumin, the intracellular concentration of curcumin was $68.1 \pm 22.3 \mathrm{ng} / \mathrm{mg}$ protein and $21.7 \pm 3.4 \mathrm{ng} / \mathrm{mg}$ 
protein for SUM149 and MCF10A respectively $(\mathrm{p}=0.03)$. The SUM149 curcumin intracellular concentration after 1 hour is three-fold higher than the MCF10A concentration, while the curcumin $\mathrm{IC}_{50}$ in SUM149 cells is two-fold lower than the $\mathrm{IC}_{50}$ in MCF10A cells. Differential cellular uptake of curcumin in the invasive breast cell line (SUM149) compared to the noninvasive cell line (MCF 10A) partially explains the differences in $\mathrm{IC}_{50}$ observed. We could not compare the intracellular curcumin concentration in primary normal human breast cells to the cell lines since they were cultured in different culture conditions (3D cultures).

Using flow cytometry, we isolated stem cell pools $\left(\mathrm{ALDH}^{+}, \mathrm{CD} 44^{+} \mathrm{CD} 24^{-}\right)$from SUM149 cells and incubated each of these cell fractions with $15 \mu \mathrm{M}$ curcumin $\pm 10 \mu \mathrm{M}$ piperine for 2 hours. We also incubated the remaining SUM149 that did not express stemness surface markers with the same curcumin \pm piperine conditions. We found no difference in intracellular curcumin concentrations in any of the stem cell fractions or in the remaining non stem SUM149 cells with piperine incubation (Figure 4). [Figure 4 should be near here]

\section{Curcumin Cellular Elimination}

We incubated MCF10A and SUM149 cells with curcumin $15 \mu \mathrm{M} \pm 10 \mu \mathrm{M}$ piperine for 1 hour, washed and reincubated with fresh media for varying time periods from 5 min to 4 hours. We found no difference in curcumin intracellular concentration or in associated concentrations of curcumin in the fresh media of the cells incubated with or without piperine (Figure 5A). The progressive reduction of curcumin concentration intracellularly is associated with rapid increases of curcumin in the extracellular media. We also detected curcumin metabolites, tetrahydrocurcumin and curcumin sulfate conjugate in very low concentrations in the extracellular media (Supplemental Figure 3). The predominant form of curcumin elimination from the cell is the parent compound, curcumin. Intracellular metabolism in neoplastic cells is 
minimal. Piperine had no effect upon curcumin elimination, either as parent compound found in the media (Figure 5B) or in the form of metabolites in the media (Supplemental Figure 3).

[Figure 5 should be near here] 


\section{Discussion}

Ayurvedic practitioners in India administer curcumin after processing it either by mixing it with other herbs or by using it in a crude turmeric preparation that consists of oils, other curcuminoids such as demethoxycurcumin, bisdemethoxycurcumin, tetrahydrocurcumin (42), and many other naturally occurring chemical excipients. The common folk-medicine practice of mixing turmeric and pepper in warm milk for treatment of respiratory or systemic inflammation, trikatu in Indian folk medicine triggered studies that showed that piperine enhances curcumin's anti-inflammatory and anticarcinogenesis effects $(7,43,44)$.

In this context and recognizing that improved analytical technologies permit a better more accurate and precise detection of curcumin and its metabolites, we assessed the cellular pharmacology of curcumin alone and in combination with piperine in a representative model of cells that mirror the carcinogenesis process. We chose cells derived from human breast neoplastic progression because of the ready availability of transformed cells (SUM149) (45), non-transformed cells (MCF10A) (46), primary normal human breast epithelial cells obtained from normal human breast mammoplasties, and cellular stemness pools that represent selfrenewing stem cells (ALDH positive) (47) and quiescent stem cells (CD44 ${ }^{+}$CD24 $4^{-}$(47). We reproduced our prior published data demonstrating additive curcumin and piperine effects in reducing normal human mammary stem cell self-renewal and proliferation (7). While we found that piperine had similar cytotoxic effects in the MCF10A cells as the SUM149, the combination of curcumin and piperine has additive but not synergistic cytotoxic effects upon MCF10A cells. This is in contrast with the synergistic cytotoxic effect of curcumin and piperine in SUM149 cells in culture. Curcumin and piperine decreased the numbers and size of primary 
mammospheres derived from normal human epithelial cells. These data suggest at least an additive antiproliferative effect between curcumin and piperine.

The data we report here demonstrate that piperine has no effect on any step in the cellular uptake, metabolism, or elimination of curcumin. Piperine's lack effect upon curcumin's cellular absorption or elimination is consistent through the carcinogenesis continuum - transformed invasive cells represented by SUM149, non-invasive neoplastic cells represented by MCF10A, and normal human breast epithelial cells in primary culture. in the models we tested.

The higher concentrations of curcumin in the media relative to its intracellular concentrations after reincubating the cells with curcumin free media suggest that curcumin is actively transported out of the cells. Berginc, et al found that piperine significantly decreased the absorbed fraction of curcumin in Caco-2 cells and in isolated rat intestine, explained on the basis of induction of the BCRP transporter enhancing curcumin efflux from cells (29). Berginc et al use of very high concentrations of both drugs, $100 \mu \mathrm{M}$ curcumin $\pm 100 \mu \mathrm{M}$ piperine, which may not accurately model the much lower curcumin and piperine concentrations that are physiologically relevant. High concentrations of curcumin and piperine might be engaging an otherwise low affinity membrane efflux system. Although pre-administration of piperine increased curcumin bioavailability in rats in vivo (28), preincubating cells with piperine did not increase curcumin's intracellular concentration.

We found that breast epithelial cells across the carcinogenesis continuum reduce curcumin to tetrahydrocurcumin and conjugate curcumin via sulfation. Piperine has no effects upon curcumin cellular reduction or sulfation. We did not explore piperine's effects on curcumin glucuronidation, since curcumin is not glucuronidated in breast cells. Piperine potently inhibits glucuronidation activity in rodent models (23). In human models, $50 \mu \mathrm{M}$ piperine did not inhibit 
glucuronidation activity $(26,48)$. Although $20 \mu \mathrm{M}$ piperine did not inhibit the glucuronidation of Epigallocatechin gallate (EGCG) in human intestinal adenocarcinoma cells (49), piperine increased the bioavailability of the EGCG in mice (49).

An important limitation of our study is that breast cells may not serve as an adequate model in assessing epithelial cell absorption or metabolism. The absorption and conjugation of curcumin is thought to be primarily an intestinal epithelial function or hepatic function. While recognizing the limitation of not using GI epithelial cellular models, we prioritized interrogating the carcinogenesis continuum at a key clinically targeted cell for breast epithelial carcinogenesis - the breast epithelial cells. Breast epithelial cell models are readily available. Since the therapeutic context of both curcumin and piperine's development are as potential breast cancer preventive agents, we considered cell models representative of the desired clinical target. Furthermore, readily available cellular carcinogenesis models that span the continuum of stemness to non-invasive and invasive neoplasms are not readily available for the human GI tract.

Based upon the data we present, we infer that the synergistic cytotoxic effects and inhibition of stem cell self-renewal of piperine with curcumin are due to their individual anticarcinogenic effect. Piperine reduces size and numbers of primary mammospheres derived from normal breast epithelial cells (antiproliferative effect), and induces cytotoxicity in transformed breast neoplastic cells, non-tumorigenic neoplastic epithelial cells. We speculate that piperine's anti-carcinogenic activity combined with curcumin may be based upon its inhibition with curcumin of one or more key stem cell control pathways such as Wnt $(7,32)$, Notch $(50)$, PI3K/AKT (51), and Hedgehog (52) or downstream control mechanisms such as AP-1 and NF$\kappa \mathrm{B}(31)$, and Stat3 (53). 


\section{Acknowledgments and Funding sources}

The authors acknowledge support from The Educational Affairs and Mission sector, Ministry of

Higher Education of Egyptian government, the University of Michigan’s Rogel Cancer Center

Cancer Prevention Fund, the Kutche Family Memorial Chair, and the Moshe Talpaz

Professorship in Translational Oncology. Support for JAC was provided by the National

Institutes of Environmental Health Sciences (R01 ES028802 and P30ES01885).

\section{Conflict of Interest Statement}

The authors declare that there are no competing interests. 


\section{References}

1 Anand P, Thomas SG, Kunnumakkara AB, Sundaram C, Harikumar KB, et al.:

Biological activities of curcumin and its analogues (Congeners) made by man and Mother

Nature. Biochem Pharmacol 76, 1590-611, 2008.

2 Selvam C, Prabu SL, Jordan BC, Purushothaman Y, Umamaheswari A, et al.: Molecular mechanisms of curcumin and its analogs in colon cancer prevention and treatment. Life Sci 239, $117032,2019$.

3 Mokbel K, Mokbel K: Chemoprevention of Breast Cancer With Vitamins and Micronutrients: A Concise Review. In Vivo 33, 983-997, 2019.

4 Mahran RI, Hagras MM, Sun D, Brenner DE: Bringing Curcumin to the Clinic in Cancer Prevention: a Review of Strategies to Enhance Bioavailability and Efficacy. AAPS J 19, 54-81, 2017.

5 Heger M, van Golen RF, Broekgaarden M, Michel MC: The molecular basis for the pharmacokinetics and pharmacodynamics of curcumin and its metabolites in relation to cancer. Pharmacol Rev 66, 222-307, 2014.

6 Patel SS, Acharya A, Ray RS, Agrawal R, Raghuwanshi R, et al.: Cellular and molecular mechanisms of curcumin in prevention and treatment of disease. Crit Rev Food Sci Nutr 60, 887939, 2020.

$7 \quad$ Kakarala M, Brenner DE, Korkaya H, Cheng C, Tazi K, et al.: Targeting breast stem cells with the cancer preventive compounds curcumin and piperine. Breast Cancer Res Treat 122, $777-85,2010$. 
8 Li X, Wang X, Xie C, Zhu J, Meng Y, et al.: Sonic hedgehog and Wnt/beta-catenin pathways mediate curcumin inhibition of breast cancer stem cells. Anticancer Drugs 29, 208$215,2018$.

9 Hanikoglu A, Kucuksayan E, Hanikoglu F, Ozben T, Menounou G, et al.: Effects of somatostatin, curcumin, and quercetin on the fatty acid profile of breast cancer cell membranes. Can J Physiol Pharmacol 98, 131-138, 2020.

10 Lopes-Rodrigues V, Sousa E, Vasconcelos MH: Curcumin as a Modulator of PGlycoprotein in Cancer: Challenges and Perspectives. Pharmaceuticals (Basel) 9, 2016.

11 Jain A, Samykutty A, Jackson C, Browning D, Bollag WB, et al.: Curcumin inhibits PhIP induced cytotoxicity in breast epithelial cells through multiple molecular targets. Cancer Lett $365,122-31,2015$.

12 Singletary K, MacDonald C, Wallig M, Fisher C: Inhibition of 7,12-

dimethylbenz[a]anthracene (DMBA)-induced mammary tumorigenesis and DMBA-DNA adduct formation by curcumin. Cancer Lett 103, 137-41, 1996.

13 Guo Y, Wu R, Gaspar JM, Sargsyan D, Su ZY, et al.: DNA methylome and transcriptome alterations and cancer prevention by curcumin in colitis-accelerated colon cancer in mice. Carcinogenesis 39, 669-680, 2018.

14 Pricci M, Girardi B, Giorgio F, Losurdo G, Ierardi E, et al.: Curcumin and Colorectal Cancer: From Basic to Clinical Evidences. Int J Mol Sci 21, 2020.

15 McFadden RM, Larmonier CB, Shehab KW, Midura-Kiela M, Ramalingam R, et al.: The Role of Curcumin in Modulating Colonic Microbiota During Colitis and Colon Cancer Prevention. Inflamm Bowel Dis 21, 2483-94, 2015. 
16 Perkins S, Verschoyle RD, Hill K, Parveen I, Threadgill MD, et al.: Chemopreventive efficacy and pharmacokinetics of curcumin in the min/+ mouse, a model of familial adenomatous polyposis. Cancer Epidemiol Biomarkers Prev 11, 535-40, 2002.

17 Shoba G, Joy D, Joseph T, Majeed M, Rajendran R, et al.: Influence of piperine on the pharmacokinetics of curcumin in animals and human volunteers. Planta Med 64, 353-6, 1998. 18 Hassanzadeh K, Buccarello L, Dragotto J, Mohammadi A, Corbo M, et al.: Obstacles against the Marketing of Curcumin as a Drug. Int J Mol Sci 21, 2020.

19 Singh DV, Godbole MM, Misra K: A plausible explanation for enhanced bioavailability of P-gp substrates in presence of piperine: simulation for next generation of P-gp inhibitors. J Mol Model 19, 227-38, 2013.

20 Bhardwaj RK, Glaeser H, Becquemont L, Klotz U, Gupta SK, et al.: Piperine, a major constituent of black pepper, inhibits human P-glycoprotein and CYP3A4. J Pharmacol Exp Ther 302, 645-50, 2002.

21 Li S, Lei Y, Jia Y, Li N, Wink M, et al.: Piperine, a piperidine alkaloid from Piper nigrum re-sensitizes P-gp, MRP1 and BCRP dependent multidrug resistant cancer cells. Phytomedicine 19, 83-7, 2011.

22 Singh J, Dubey RK, Atal CK: Piperine-mediated inhibition of glucuronidation activity in isolated epithelial cells of the guinea-pig small intestine: evidence that piperine lowers the endogeneous UDP-glucuronic acid content. J Pharmacol Exp Ther 236, 488-93, 1986.

23 Reen RK, Jamwal DS, Taneja SC, Koul JL, Dubey RK, et al.: Impairment of UDPglucose dehydrogenase and glucuronidation activities in liver and small intestine of rat and guinea pig in vitro by piperine. Biochem Pharmacol 46, 229-38, 1993. 
24 Fong YK, Li CR, Wo SK, Wang S, Zhou L, et al.: In vitro and in situ evaluation of herbdrug interactions during intestinal metabolism and absorption of baicalein. J Ethnopharmacol $141,742-53,2012$.

25 Shamsi S, Tran H, Tan RS, Tan ZJ, Lim LY: Curcumin, Piperine, and Capsaicin: A Comparative Study of Spice-Mediated Inhibition of Human Cytochrome P450 Isozyme Activities. Drug Metab Dispos 45, 49-55, 2017.

26 Volak LP, Ghirmai S, Cashman JR, Court MH: Curcuminoids inhibit multiple human cytochromes P450, UDP-glucuronosyltransferase, and sulfotransferase enzymes, whereas piperine is a relatively selective CYP3A4 inhibitor. Drug Metab Dispos 36, 1594-605, 2008. 27 Munjal B, Pawar YB, Patel SB, Bansal AK: Comparative oral bioavailability advantage from curcumin formulations. Drug Deliv Transl Res 1, 322-31, 2011.

28 Chen Z, Sun D, Bi X, Zeng X, Luo W, et al.: Pharmacokinetic based study on "lagged stimulation" of Curcumae Longae Rhizoma - Piper nigrum couplet in their main active components' metabolism using UPLC-MS-MS. Phytomedicine 27, 15-22, 2017.

29 Berginc K, Trontelj J, Basnet NS, Kristl A: Physiological barriers to the oral delivery of curcumin. Pharmazie 67, 518-24, 2012.

30 Colacino JA, McDermott SP, Sartor MA, Wicha MS, Rozek LS: Transcriptomic profiling of curcumin-treated human breast stem cells identifies a role for stearoyl-coa desaturase in breast cancer prevention. Breast Cancer Res Treat 158, 29-41, 2016.

31 Do MT, Kim HG, Choi JH, Khanal T, Park BH, et al.: Antitumor efficacy of piperine in the treatment of human HER2-overexpressing breast cancer cells. Food Chem 141, 2591-9, 2013. 
32 de Almeida GC, Oliveira LFS, Predes D, Fokoue HH, Kuster RM, et al.: Piperine suppresses the Wnt/beta-catenin pathway and has anti-cancer effects on colorectal cancer cells. Sci Rep 10, 11681, 2020.

33 Dontu G, Abdallah WM, Foley JM, Jackson KW, Clarke MF, et al.: In vitro propagation and transcriptional profiling of human mammary stem/progenitor cells. Genes Dev 17, 1253-70, 2003.

34 Wang YJ, Pan MH, Cheng AL, Lin LI, Ho YS, et al.: Stability of curcumin in buffer solutions and characterization of its degradation products. J Pharm Biomed Anal 15, 1867-76, 1997.

35 Schneider C, Gordon ON, Edwards RL, Luis PB: Degradation of Curcumin: From Mechanism to Biological Implications. J Agric Food Chem 63, 7606-14, 2015.

36 Liu S, Cong Y, Wang D, Sun Y, Deng L, et al.: Breast cancer stem cells transition between epithelial and mesenchymal states reflective of their normal counterparts. Stem Cell Reports 2, 78-91, 2014.

37 Pieke EN, Granby K, Trier X, Smedsgaard J: A framework to estimate concentrations of potentially unknown substances by semi-quantification in liquid chromatography electrospray ionization mass spectrometry. Anal Chim Acta 975, 30-41, 2017.

38 Chou TC, Talalay P: Quantitative analysis of dose-effect relationships: the combined effects of multiple drugs or enzyme inhibitors. Adv Enzyme Regul 22, 27-55, 1984.

39 Chou TC: Drug combination studies and their synergy quantification using the ChouTalalay method. Cancer Res 70, 440-6, 2010.

40 Trapnell C, Hendrickson DG, Sauvageau M, Goff L, Rinn JL, et al.: Differential analysis of gene regulation at transcript resolution with RNA-seq. Nat Biotechnol 31, 46-53, 2013. 
41 Colacino JA, E. Brooks, M. Fouladdel, S. McDermottm, SP. Lee, M. Hill, D. Sartor, M.

Rozek, L. Wicha, M. Heterogeneity of normal human breast stem and progenitor cells as revealed by transcriptional profiling: bioRxiv, 2017.

42 Aggarwal BB, Sundaram C, Malani N, Ichikawa H: Curcumin: the Indian solid gold. Adv Exp Med Biol 595, 1-75, 2007.

43 Sehgal A, Kumar M, Jain M, Dhawan DK: Combined effects of curcumin and piperine in ameliorating benzo(a)pyrene induced DNA damage. Food Chem Toxicol 49, 3002-6, 2011.

44 Patial V, S M, Sharma S, Pratap K, Singh D, et al.: Synergistic effect of curcumin and piperine in suppression of DENA-induced hepatocellular carcinoma in rats. Environ Toxicol Pharmacol 40, 445-52, 2015.

45 Hoffmeyer MR, Wall KM, Dharmawardhane SF: In vitro analysis of the invasive phenotype of SUM 149, an inflammatory breast cancer cell line. Cancer Cell Int 5, 11, 2005. 46 Soule HD, Maloney TM, Wolman SR, Peterson WD, Jr., Brenz R, et al.: Isolation and characterization of a spontaneously immortalized human breast epithelial cell line, MCF-10. Cancer Res 50, 6075-86, 1990.

47 Ingthorsson S, Briem E, Bergthorsson JT, Gudjonsson T: Epithelial Plasticity During Human Breast Morphogenesis and Cancer Progression. J Mammary Gland Biol Neoplasia 21, 139-148, 2016.

48 Gulseren I, Guri A, Corredig M: Effect of interfacial composition on uptake of curcuminpiperine mixtures in oil in water emulsions by Caco-2 cells. Food Funct 5, 1218-23, 2014.

49 Lambert JD, Hong J, Kim DH, Mishin VM, Yang CS: Piperine enhances the bioavailability of the tea polyphenol (-)-epigallocatechin-3-gallate in mice. J Nutr 134, 1948-52, 2004. 
50 Sun XD, Liu XE, Huang DS: Curcumin reverses the epithelial-mesenchymal transition of pancreatic cancer cells by inhibiting the Hedgehog signaling pathway. Oncol Rep 29, 2401-7, 2013.

51 Chen H, Sheng H, Zhao Y, Zhu G: Piperine Inhibits Cell Proliferation and Induces Apoptosis of Human Gastric Cancer Cells by Downregulating Phosphatidylinositol 3-Kinase (PI3K)/Akt Pathway. Med Sci Monit 26, e928403, 2020.

52 Lian N, Jiang Y, Zhang F, Jin H, Lu C, et al.: Curcumin regulates cell fate and metabolism by inhibiting hedgehog signaling in hepatic stellate cells. Lab Invest 95, 790-803, 2015.

53 Song L, Wang Y, Zhen Y, Li D, He X, et al.: Piperine inhibits colorectal cancer migration and invasion by regulating STAT3/Snail-mediated epithelial-mesenchymal transition. Biotechnol Lett 42, 2049-2058, 2020. 


\section{Figure Captions}

Figure 1. Curcumin is unstable in physiologic solution. A. Curcumin was incubated in either phosphate buffered saline (PBS) or cell media (DMEM/F12 Lonza supplemented with 5\% fetal bovine serum, insulin, hydrocortisone) protected from light at $37^{\circ} \mathrm{C}$. Samples were then extracted and assayed by LC-MS. Data presented as the percent of curcumin concentration detected to the curcumin concentration at time zero. Within 8 hours, $50 \%$ of curcumin is degraded to degradation products. B. Curcumin's primary degradation product, bicyclopentadione increases in concentration over time in both PBS and media commiserate with the decline in curcumin. C. Piperine does not enhance curcumin stability in PBS. Piperine 10 $\mu \mathrm{M}$ was added to curcumin in the same conditions as shown in panel A. No difference in degradation rate of curcumin was found.

\section{Figure 2. Curcumin \pm piperine effects on viability of invasive and non-invasive neoplastic}

breast cells. Percent of viable MCF10A (A) and SUM149 cells (B) after treatment with curcumin and piperine compared to controls treated with the DMSO vehicle $(0.1 \%)$ for 72 hours. Results expressed as the mean \pm SD of two independent experiments 6 replicates each. Combination index (CI) plots for the effect of combining curcumin and piperine on the fraction of living SUM149 (B) and MCF10A (C) cells. Two points in Panel B showing antagonism were curcumin concentrations of $20 \mu \mathrm{M}$, a cytotoxic concentration. CI value $<0.9$ indicates synergy, between 0.9-1.1 indicates additive effects and $>1.1$ indicates antagonistic effects. 
Figure 3. Cellular uptake of curcumin is not altered by piperine. Panel A: Intracellular curcumin concentration after incubating MCF10A, SUM149, and normal human breast cells (nBC) with $15 \mu \mathrm{M}$ curcumin $\pm 10 \mu \mathrm{M}$ piperine for $6 \mathrm{hrs}$. Panel B: Intracellular curcumin concentration after incubating MCF10A, SUM149 with $5 \mu \mathrm{M}$ curcumin $\pm 5 \mu \mathrm{M}$ piperine for 24 hrs. Results are expressed as the mean \pm SD from triplicates. $\mathrm{nBC}=$ normal human breast cells.

Figure 4. Intracellular concentrations of curcumin in $\mathrm{ALDH}^{+}, \mathrm{ALDH}^{-}, \mathrm{CD}^{+} 4^{+} \mathrm{CD}^{-}$cells isolated from SUM 149 cells. After incubating $\mathrm{ALDH}^{+}, \mathrm{ALDH}^{-}, \mathrm{CD}^{4} 4^{+} \mathrm{CD} 24^{-}$, or the remaining SUM149 cells that did not express stemness cell surface markers (non-stem cells) with $15 \mu \mathrm{M}$ curcumin $\pm 10 \mu \mathrm{M}$ piperine for one hour the concentrations of curcumin were not affected by piperine co-incubation. $\mathrm{C}=$ curcumin, $\mathrm{C}+\mathrm{P}=$ curcumin + piperine.

Figure 5. Curcumin elimination after incubation with piperine. SUM149 and MCF10A cells were incubated with curcumin $15 \mu \mathrm{M} \pm$ piperine $10 \mu \mathrm{M}$ for 1 hour. The cells were washed and reincubated in fresh media. Panel A: Intracellular concentrations of curcumin. Panel B: Concentration of curcumin in the media. Panel C: Ratio of the curcumin mass detected by the LC-MS system in the media to the cell. Intracellular or media curcumin concentrations did not differ between the curcumin alone and the curcumin + piperine incubation groups. 


\section{Figure 1}
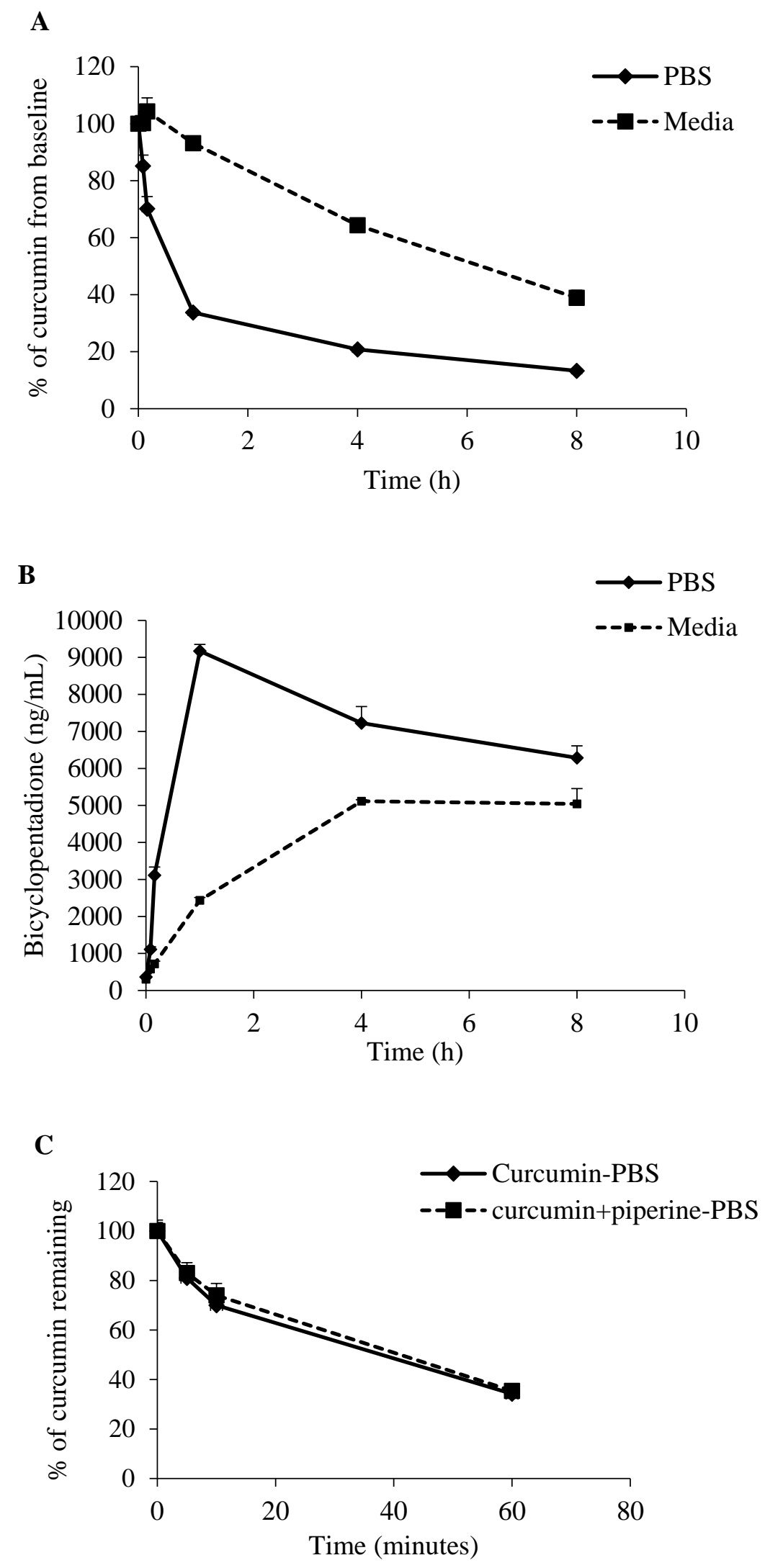


\section{Figure 2}
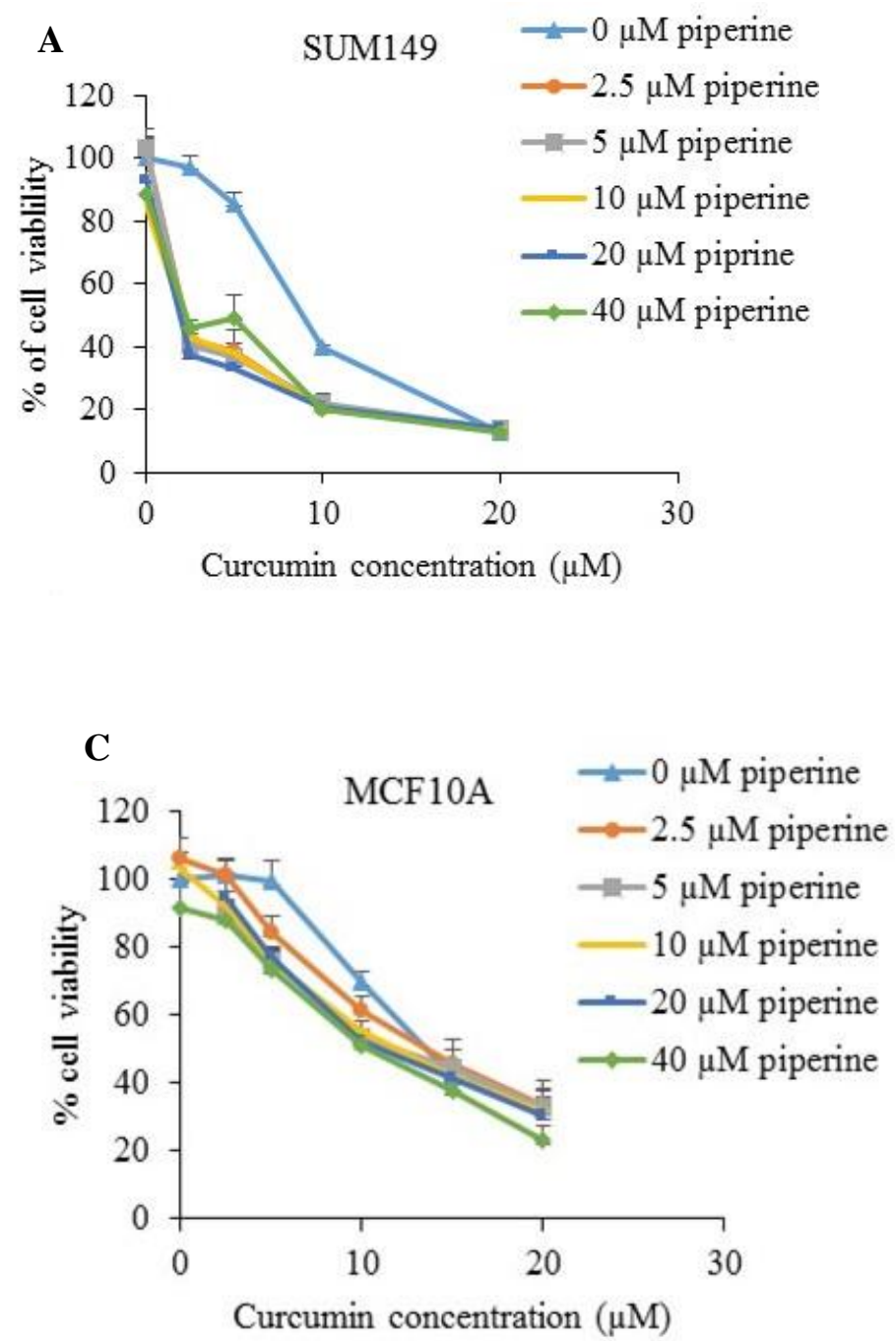
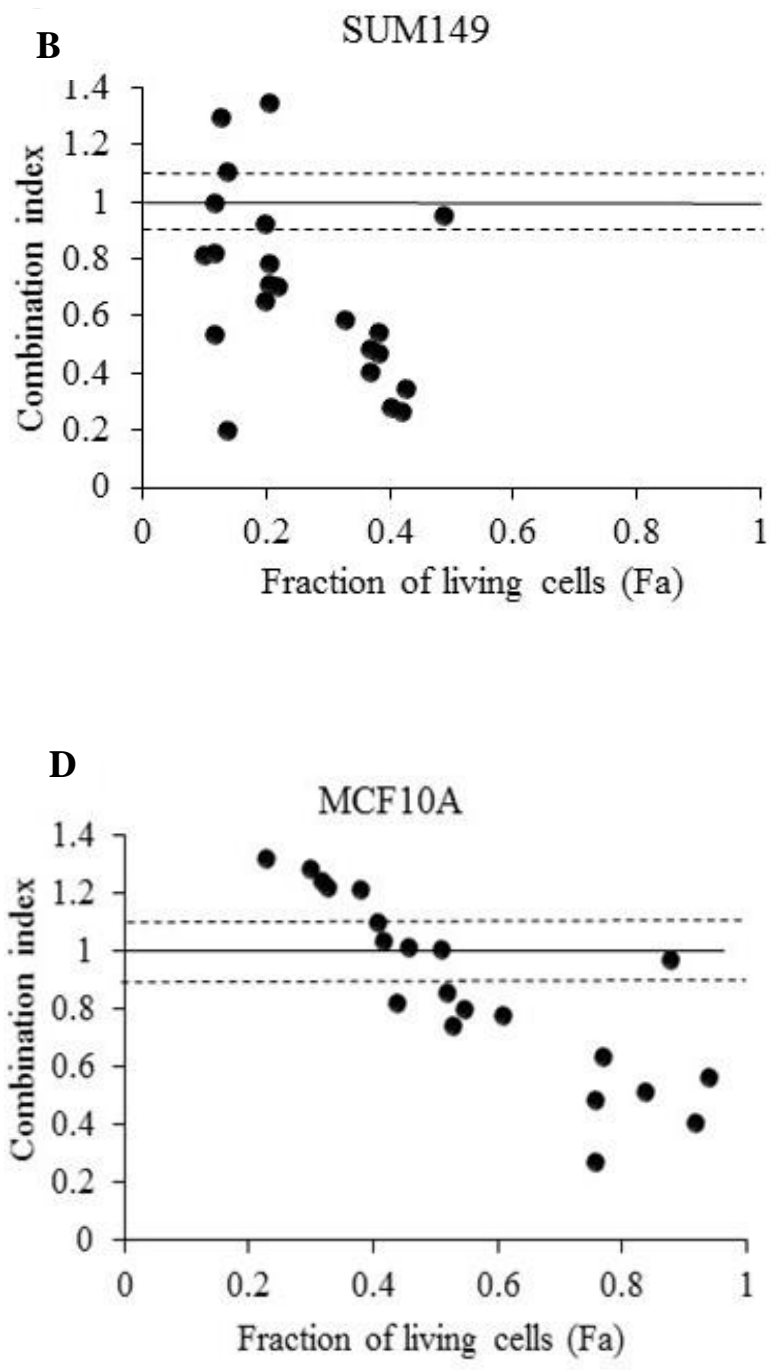


\section{Figure 3}

A

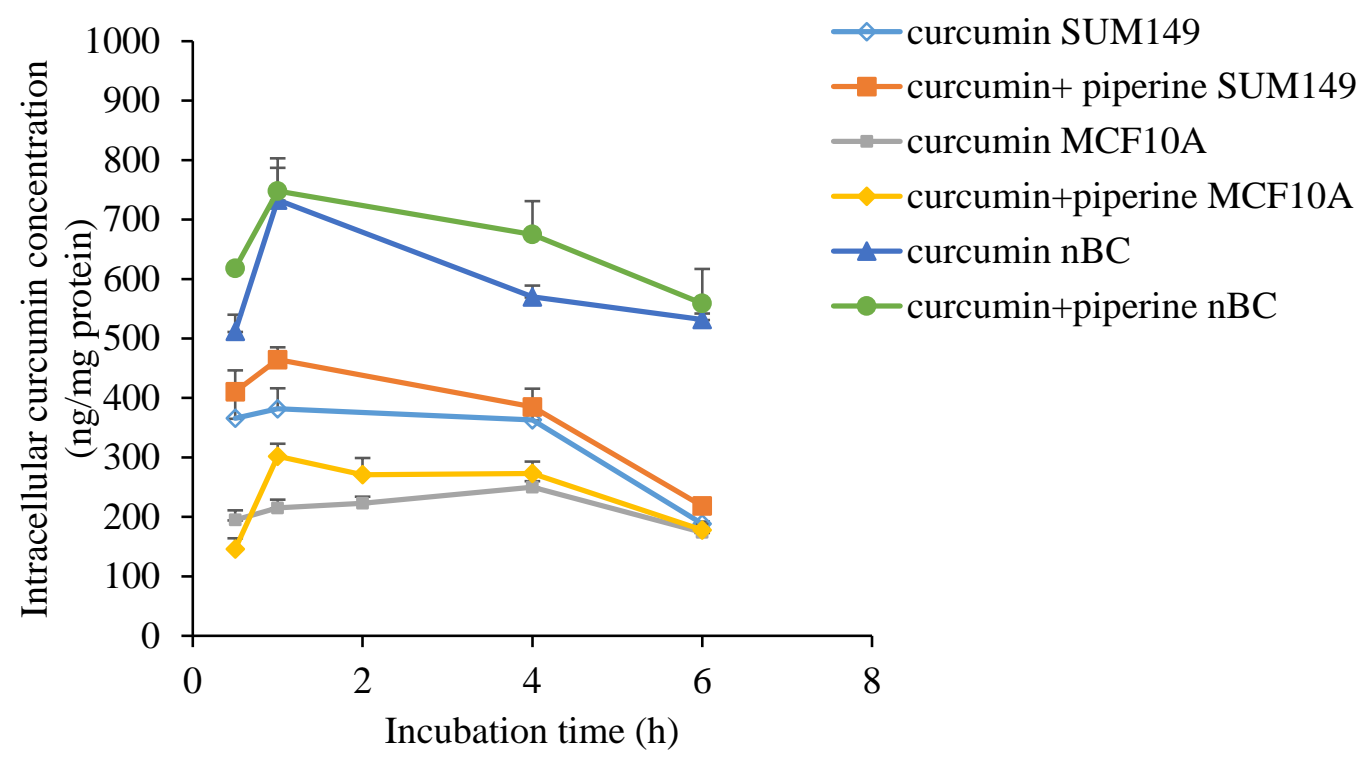

B

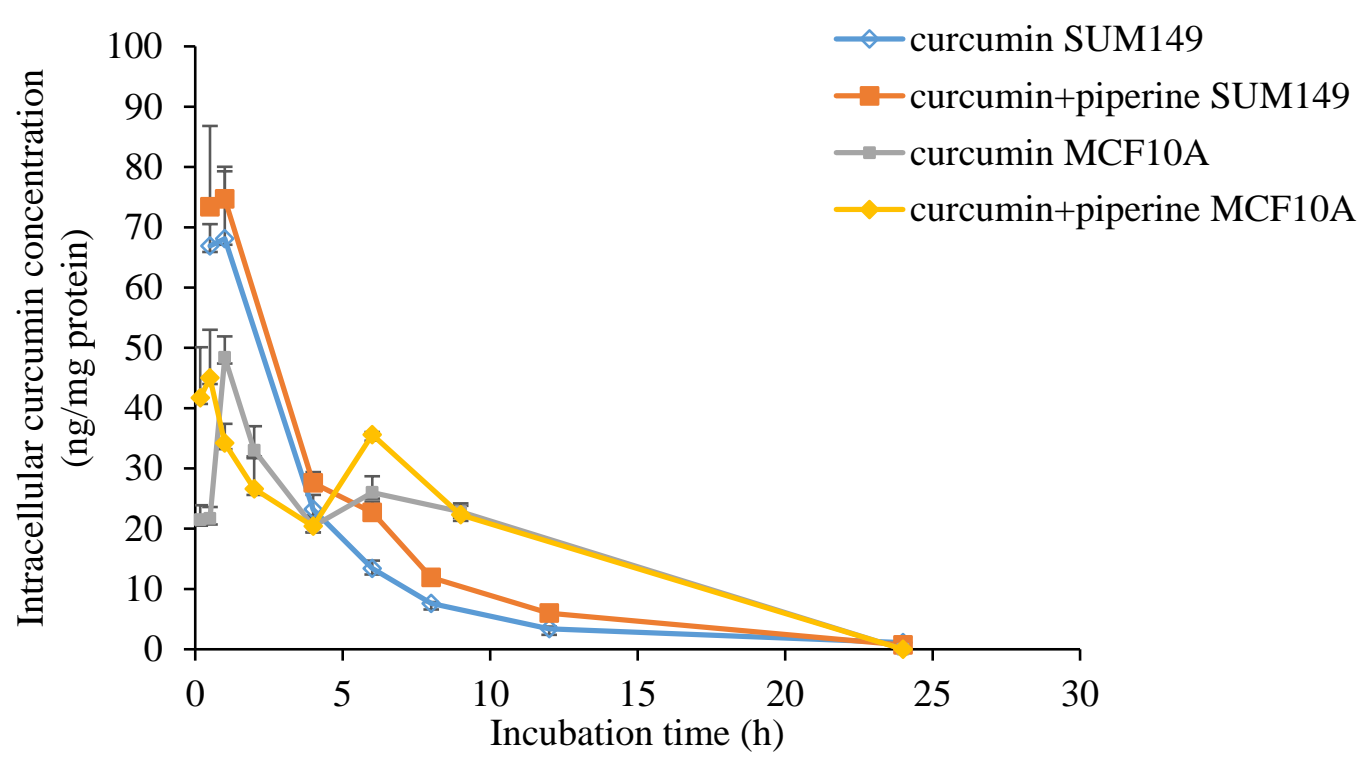




\section{Figure 4}

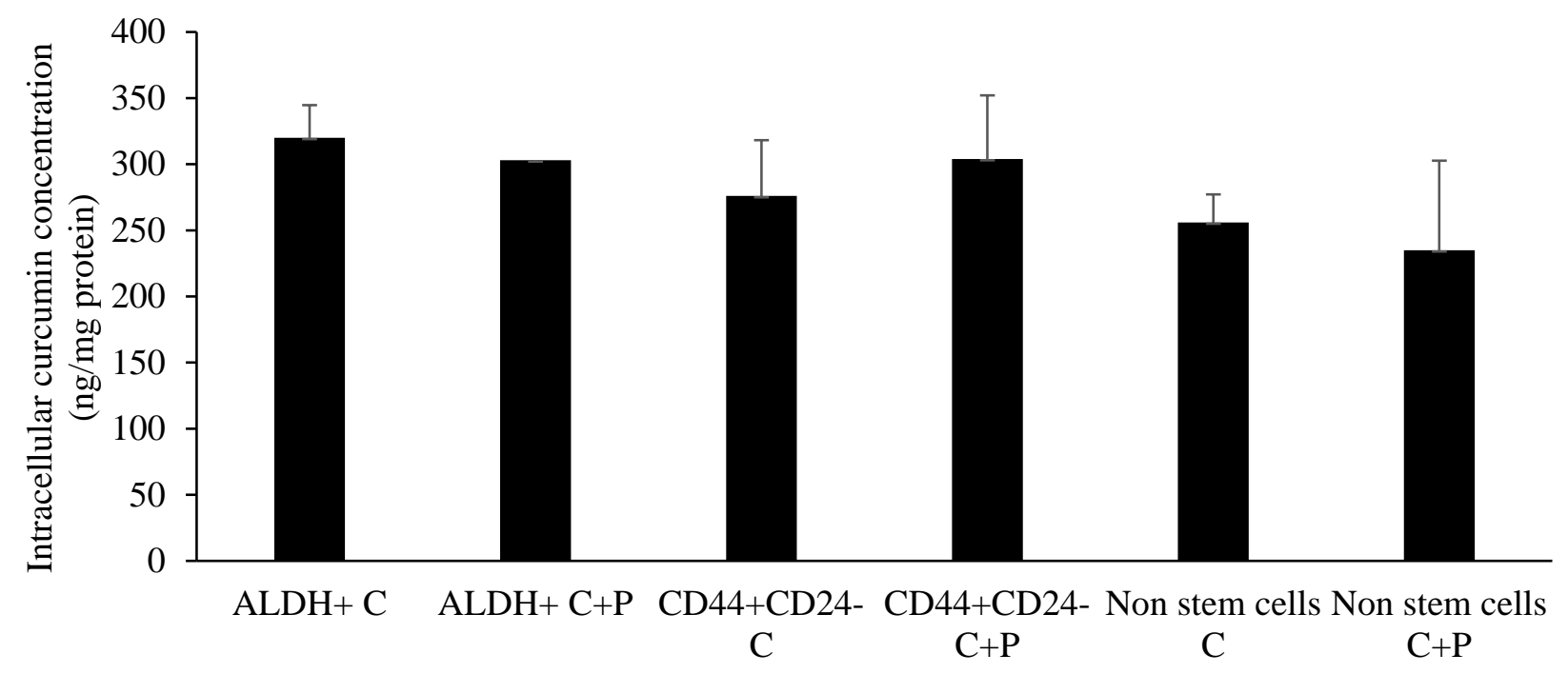




\section{Figure 5}
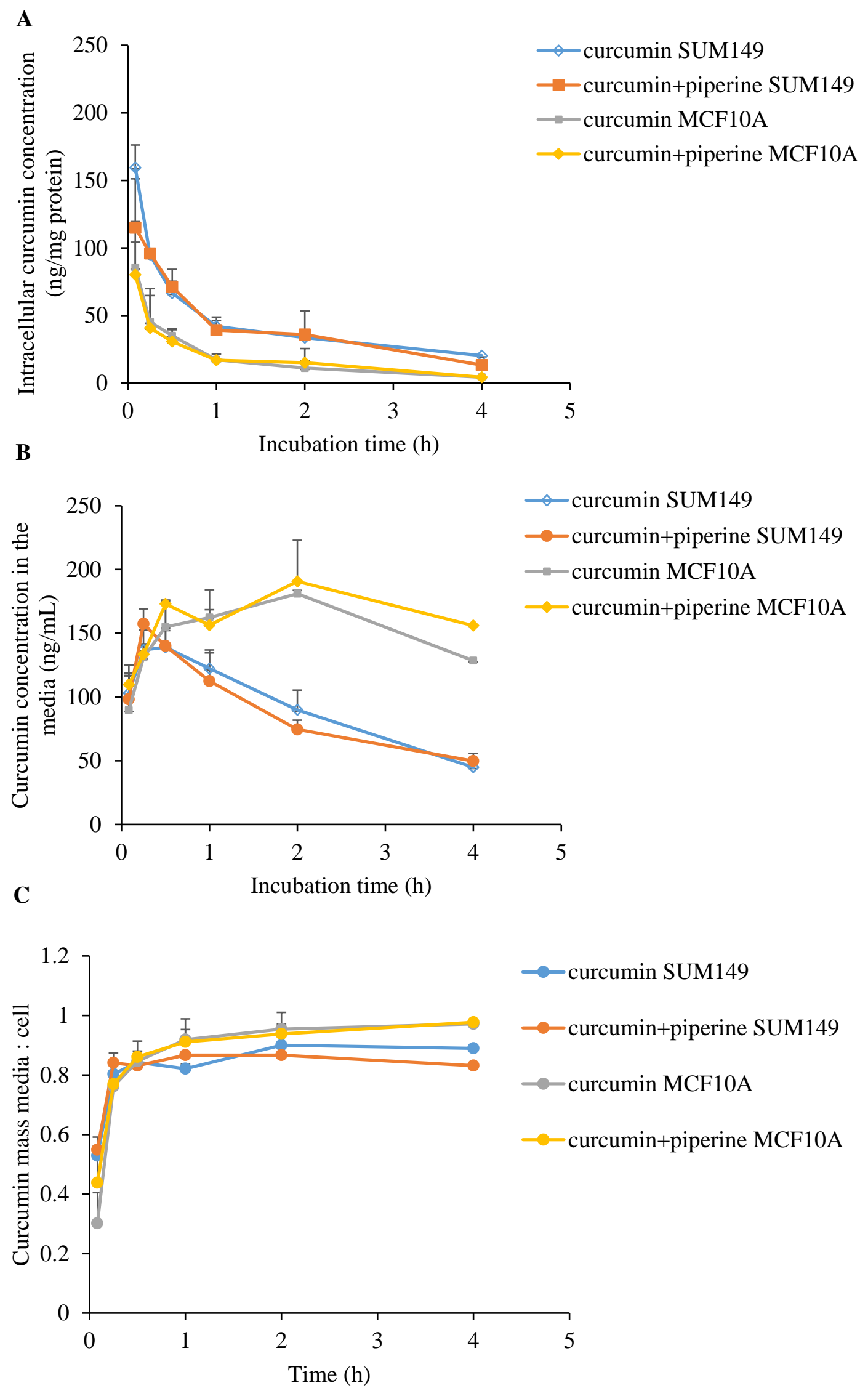